\title{
When is CRMO NOT CRMO?
}

\section{A McMahon* and C Pilkington}

\author{
Address: Great Ormond Street Hospital, London, UK
}

* Corresponding author

\author{
from $15^{\text {th }}$ Paediatric Rheumatology European Society (PreS) Congress \\ London, UK. 14-17 September 2008 \\ Published: 15 September 2008 \\ Pediatric Rheumatology 2008, 6(SuppI I):PI90 doi:I0.I I86/I546-0096-6-SI-PI90
}

This abstract is available from: http://www.ped-rheum.com/content/6/SI/PI90

(c) 2008 McMahon and Pilkington; licensee BioMed Central Ltd.

A 3 year old girl presented with a limp and a hot, swollen ankle. X-Ray showed active osteomyelitis. ESR $>60 \mathrm{~mm} /$ hr, Hb $11.3 \mathrm{~g} / \mathrm{dl}$, WCC $7.9 \times 10^{9} / \mathrm{L}$, Platelets $808 \times 10^{9} / \mathrm{L}$. Intravenous antibiotics were commenced. One week later, the left ankle became swollen, X-Ray showed osteomyelitis. Bone scan showed several areas of increased uptake, right femoral neck, both knees, both ankles, and scapula. A presumptive diagnosis of chronic recurrent multifocal osteomyelitis was made. Management was with intravenous followed by oral antibiotics. Upon rheumatology review 4 months later, she had clinically improved, nonsteroidal anti-inflammatory agents were advised, it was felt a bone biopsy was not indicated.

2 months later, she had developed episodic lower back pain, both day and night. She did not like walking and had lost weight. She was pale and had developed a kyphosis in L2-3 region with a scoliosis. Spinal X-Ray revealed multiple crush fractures with marked osteopenia. Repeat bloods showed Hb $7.0 \mathrm{~g} / \mathrm{dl}$, WCC $17 \times 10^{9} / \mathrm{L}$ and platelet count of $200 \times 10^{9} / \mathrm{L}$. Blood film demonstrated multiple lymphoblasts. Bone marrow examination revealed common acute lymphoblastic leukaemia.

At presentation, chronic recurrent multifocal osteomyelitis may mimic acute osteomyelitis; however, definitive diagnosis is with a bone biopsy. Bone scans can be useful to identify additional foci of involvement that can be present concurrently or sequentially. One case report of CRMO following ALL has been documented [1]. This case illustrates a rare presentation of CRMO clinical symptomatology and radiological findings with an underlying diagnosis of ALL.

\section{References}

I. Abril JC, Castillo F, Loewinsonh AF, Rivas C, Bernacer M: Chronic recurrent multifocal osteomyelitis after acute lymphoblastic leukaemia. Int Orthop 1994, 18(2): 126-8. 